Arq. Bras. Med. Vet. Zootec., v.66, n.6, p.1874-1882, 2014

\title{
Ureia e glicerina bruta como aditivos na ensilagem de cana-de-açúcar
}

[Urea and crude glycerin as additive in sugar cane silage]

\author{
A.M. Dias ${ }^{1 *}$, L.C.V. Ítavo ${ }^{1}$, C.C.B.F. Ítavo ${ }^{1}$, L.R. Blan ${ }^{2}$, E.N.O. Gomes ${ }^{1}$, C.M. Soares ${ }^{1}$, \\ E.S. Leal $^{2}$, E. Nogueira ${ }^{3}$, E.M. Coelho ${ }^{4}$ \\ ${ }^{1}$ Universidade Federal de Mato Grosso do Sul - UFMS/FAMEZ - Campo Grande, MS \\ ${ }^{2}$ Universidade Católica Dom Bosco - UCDB - Campo Grande, MS \\ ${ }^{3}$ Embrapa - Centro de Pesquisa Agropecuária do Pantanal - CPAP - Corumbá, MS \\ ${ }^{4}$ Universidade Federal de Santa Maria - UFSM - Santa Maria, RS
}

\begin{abstract}
RESUMO
Objetivou-se avaliar a inclusão de ureia e glicerina bruta como aditivos na ensilagem da cana-de-açúcar, na composição químico-bromatológica, $\mathrm{pH}, \mathrm{N}$-amoniacal $\left(\mathrm{N}-\mathrm{NH}_{3}\right)$ e digestibilidade in vitro (DIV). Os tratamentos foram quatro doses de ureia, 0, 10, 20 e $30 \mathrm{~g}$ de ureia por kg de cana-de-açúcar na ensilagem, e cinco doses de glicerina bruta, 0, 10, 20, 30 e 40g de glicerina bruta por kg de cana-de-açúcar na ensilagem. As silagens foram armazenadas por 180 dias. O tratamento com ureia afetou a maioria das variáveis relacionadas ao valor nutritivo, aumentando os teores de matéria seca (MS) e proteína (PB) (2,58; 7,76; 18,70 e 19,31\%), reduzindo os teores de fibra em detergente neutro (FDN) e melhorando a DIV da MS (42,61; 48,53; 50,69 e 51,18\%) e FDN (38,81; 39,23; 41,06 e 43,46\%), e as características fermentativas da silagem, apresentando valores de $\mathrm{pH}$ de 3,49; 3,86; 4,18 e 3,93 e de $\mathrm{N}_{-} \mathrm{NH}_{3}$ de 1,72; 3,80; 7,88 e 9,00, para as dose de 0, 10, 20 e $30 \mathrm{~g}$, respectivamente. A glicerina bruta aumentou os teores de MS e extrato etéreo (1,45; 3,03; 3,62; 3,41 e 4,38\%), melhorou a DIV da MS com valores de 49,61; 52,24; 53,28; 55,60 e 56,09\% e reduziu perdas por gases durante o processo de fermentação, apresentando médias de 6,69; 5,97; 5,89; 5,51 e 5,48\% da MS para as doses 0, 10, 20, 30 e 40g, respectivamente. Assim, a ureia e a glicerina bruta podem ser utilizadas como aditivos na ensilagem da cana-de-açúcar.
\end{abstract}

Palavras-chave: conservação de forragem, glicerol, silagem

\begin{abstract}
The aim of this study was to evaluate the inclusion of urea and crude glycerin as an additive in ensiling of sugar cane, in chemical composition, $\mathrm{pH}$, ammonia- $\mathrm{N}\left(\mathrm{N}-\mathrm{NH}_{3}\right)$ and in vitro digestibility (IVD). The treatments were four doses of urea $0,10,20$ and $30 \mathrm{~g}$ per $\mathrm{kg}$ of sugar cane ensiling and five doses of crude glycerin 0,10, 20, 30 and 40g per $\mathrm{kg}$ of crude glycerin sugar cane ensiling. The silages were stored for 180 days. Treatment with urea affected most variables related to nutritional value, increasing the concentrations of dry matter (DM) and protein (CP) (2.58, 7.76, 18.70 and 19.31\%) and reduced levels of neutral detergent fiber (NDF) and improved IVDDM (42.61, 48.53, 50.69 and 51.18\%) and NDF (38.81, 39.23, 41.06 and 43.46\%) and fermentation characteristics of silage, with $\mathrm{pH}$ values of 3.49, 3.86, 4.18 and 3.93 and NH3 1.72, 3.80, 7.88 and 9.00 for the dose of 0,10, 20 and $30 \mathrm{~g}$, respectively. The crude glycerin increased in DM and ether extract (1.45, 3.03, 3.62, 3.41 and 4.38\%), improved IVDDM with values of 49.61, 52.24, 53 28; 55.60 and 56.09\% and reduced gas losses during the fermentation process with mean of 6.69, 5.97, 5.89, 5.51 and 5.48\% of DM for the doses 0, $10,20,30$ and 40g, respectively. Urea and crude glycerin can be used as an additive in ensiling of sugar cane.
\end{abstract}

Keywords: forage conservation, glycerol, silage

Recebido em 5 de junho de 2014

Aceito em 15 de outubro de 2014

E-mail: alexandre.menezes@ufms.br 


\section{INTRODUÇÃo}

Uma das dificuldades em se utilizar a cana-deaçúcar in natura estaria relacionada à necessidade de corte diário. Uma alternativa seria a ensilagem, o que pode reduzir o corte frequente, diminuindo assim o trabalho com mão de obra e o deslocamento de máquinas na propriedade.

$\mathrm{Na}$ ensilagem da cana-de-açúcar sem uso de aditivos, pode ocorrer intensa fermentação devido à atividade de leveduras que utilizam os açúcares para seu crescimento, produzindo etanol, ocasionando perdas no valor nutritivo da forragem. Na ensilagem da cana-de-açúcar, onde a queda do $\mathrm{pH}$ é rápida, as leveduras dominam o processo fermentativo, pois não são inibidas pela redução do $\mathrm{pH}$ no alimento. Evangelista et al. (2009), avaliando a ensilagem da cana-de-açúcar, observaram redução do $\mathrm{pH}$ a valores inferiores a 4,0 aos três dias de fermentação, o que seria desejável a qualquer silagem.

A ureia, quando em contato com a forragem ensilada, é hidrolisada a amônia, que tem efeito inibidor sobre a população de leveduras e mofos, o que favorece a redução da produção de etanol e perdas de matéria seca (MS) em silagem de canade-açúcar (Alli et al., 1983). Ribeiro et al. (2010), estudando os efeitos da ureia e hidróxido de sódio como aditivos na ensilagem da cana-deaçúcar, verificaram que ambos diminuem as perdas e reduzem os constituintes da parede celular das silagens. Entretanto, Castro Neto et al. (2008) não observaram efeito benéfico da ureia sobre a qualidade da silagem.

Na produção do biodiesel, o seu principal subproduto é o glicerol (glicerina). A glicerina resultante desse processo, denominada glicerina bruta, contém, em média, de 75 a $80 \%$ de glicerol, sendo o restante composto por água, ácidos graxos (7 a 13\%), minerais oriundo dos catalisadores (2 a 3\%) e álcool $(<0,5 \%)$ (Kerr et al., 2009).

No entanto, há poucas referências sobre a adição de glicerina bruta durante o processo de ensilagem; porém, pela grande disponibilidade de glicerina bruta decorrente da produção de biodiesel e pelo poder de compensar a perda energética da silagem de cana, torna-se interessante estudá-la como aditivo na silagem.
Gomes (2013) verificou que a glicerina é um promissor aditivo para silagens de cana-deaçúcar, capaz de enriquecer a densidade energética e melhorar a estabilidade aeróbia do material ensilado.

Assim, objetivou-se avaliar a inclusão de ureia ou de glicerina bruta como aditivo na ensilagem da cana-de-açúcar, por meio da composição químico-bromatológica, $\mathrm{pH}, \mathrm{N}$-amoniacal e digestibilidade in vitro.

\section{MATERIAL E MÉTODOS}

A cultivar da cana-de-açúcar utilizada foi a Var. RB7515, com 15 meses de rebrota. A forragem de cana-de-açúcar foi colhida utilizando-se colhedora de forragem regulada para o corte em partículas de $2 \mathrm{~cm}$ de comprimento. Para confecção das silagens foram utilizados silos experimentais de PVC, com $10 \mathrm{~cm}$ de diâmetro e $50 \mathrm{~cm}$ de altura, com aplicação de uma densidade de compactação de aproximadamente $600 \mathrm{~kg} / \mathrm{m}^{3}$ por silo.

Os tratamentos foram compreendidos por doses de glicerina bruta e ureia pecuária como aditivos na ensilagem da cana-de-açúcar, sendo quatro doses de ureia pecuária, 0, 10, 20 e 30g de ureia por kg de cana-de-açúcar na ensilagem, e cinco doses de glicerina bruta, 0, 10, 20, 30 e 40g de glicerina bruta por $\mathrm{kg}$ de cana-de-açúcar na ensilagem. Para cada tratamento foram confeccionados quatro silos. O delineamento experimental foi inteiramente casualizado, com quatro repetições.

A composição química da glicerina bruta utilizada como aditivo foi de 72,50\% de matéria seca (MS), 96,00\% de matéria orgânica (MO), 0,3\% de proteína bruta (PB) e 10,80\% de extrato etéreo (EE).

Após a colheita da cana-de-açúcar, foram formados montes com $100 \mathrm{~kg}$ de massa verde e adicionados os aditivos com as respectivas doses. Após a homogeneização da cana-de-açúcar com os aditivos (ureia e glicerina bruta), os silos foram confeccionados. A compactação foi realizada com soquetes de cimento produzidos especificamente para esse fim. Após a compactação do material, os silos foram vedados com tampas de PVC, pesados e armazenados. 
Após 180 dias de conservação, os silos experimentais foram abertos. Retiraram-se amostras de cada unidade experimental no momento da abertura, sendo retirado todo o conteúdo do silo, homogeneizado e coletadas três amostras por minissilo, sendo desprezados $15 \mathrm{~cm}$ da parte superior do silo.

Foram determinados os teores de matéria seca (MS), matéria orgânica (MO), proteína bruta (PB), extrato etéreo (EE), fibra em detergente neutro (FDN) e fibra em detergente ácido (FDA), conforme metodologias descritas em Silva e Queiroz (2002).

Para a análise de $\mathrm{pH}$, foram coletadas subamostras de $25 \mathrm{~g}$, foram adicionados $100 \mathrm{~mL}$ de água e, após repouso de 2 horas, realizou-se a leitura de $\mathrm{pH}$, utilizando-se potenciômetro. Para determinação do $\mathrm{N}$-amoniacal $\left(\mathrm{N}-\mathrm{NH}_{3}\right)$, foi coletada uma subamostra de $25 \mathrm{~g}$, sendo adicionados $200 \mathrm{~mL}$ de uma solução de $\mathrm{H}_{2} \mathrm{SO}_{4}$ $(0,2 \mathrm{~N})$, permanecendo em repouso por 48 horas e, em seguida, realizou-se a filtragem em papel de filtro Whatman 54, sendo que esse filtrado foi armazenado em geladeira para posterior determinação do $\mathrm{N}^{-\mathrm{NH}_{3}}$ (Bolsen et al., 1992).

Após a compactação e fechamento do silo (dia zero), os silos foram pesados e, aos 180 dias de fermentação, foram pesados novamente para determinação das perdas (Perdas) por gases e, em seguida, foram abertos. As perdas por gases foram medidas conforme equação adaptada por Jobim et al. (2007):

$\mathrm{P}(\%)=[($ PSen - Pten $) *$ MSen $]-[($ PSab - Pen $)$

* MSab] / [(PSen -Pten) * MSen] x 100.

onde: $\mathrm{P}=$ Perdas por gases em $\%$ da MS; PSen = Peso do silo cheio na ensilagem (kg); Pten = Peso do conjunto (silo+tampa) na ensilagem (kg); MSen = Teor de MS da forragem na ensilagem (\%); PSab = Peso do silo cheio na abertura (kg); MSab = Teor de MS da forragem na abertura (\%).

Foram avaliadas as digestibilidades in vitro da matéria seca (DIVMS), da fibra em detergente neutro (DIVFDN) e da fibra em detergente ácido (DIVFDA). Para determinação da digestibilidade in vitro, foi adicionado $1 \mathrm{~g}$ de substrato em saquinhos de TNT $4 \times 4 \mathrm{~cm}$, previamente tarados e numerados. Em seguida, os 20 saquinhos foram acomodados em jarros com capacidade de 5 litros, aos quais foram adicionados 1,6 litros de saliva artificial de Mcdougall (com 0,1\% glicose e ureia, $\mathrm{pH}=8,5$ ); borbulhado o meio com $\mathrm{CO}_{2}$ até o pH atingir 6,9, vedaram-se os jarros contendo válvula de Bunsen e foram colocados na incubadora Daisy II - ANKOM; adicionaramse $400 \mathrm{~mL}$ de líquido ruminal de bovino (coado e transportado em garrafa térmica; borbulhado o meio com $\mathrm{CO}_{2}$ e incubado em $39^{\circ} \mathrm{C}$ por 48 horas, fazendo agitações constantes; ao final foi adicionado $40 \mathrm{~mL}$ de $\mathrm{HCl} 6 \mathrm{~N}+$ pepsina (8 gramas), e mantendo agitação por mais 24 horas). Ao final, os saquinhos foram drenados, lavados e secos a $105^{\circ} \mathrm{C}$; foram utilizados saquinhos em branco (sem amostras) para correção de impurezas.

Os dados foram analisados por meio de análise de variância e regressão utilizando-se o Sistema de Análises Estatísticas e Genéticas - SAEG. Os modelos foram escolhidos com base na significância dos coeficientes de regressão utilizando-se o teste Tukey, adotando 5\% de probabilidade.

\section{RESULTADOS E DISCUSSÃO}

As doses de ureia como aditivo para a cana-deaçúcar no momento da ensilagem apresentaram efeito linear positivo $(\mathrm{P}<0,05)$ para os teores de MS, MO e PB, porém não foi observado efeito significativo para o teor de EE (Tab. 1). Ao adicionar a ureia na cana-de-açúcar na ensilagem, o teor de MS da silagem aumentou significativamente, proporcionando maior teor de MS e, consequentemente, de MO. A ureia como aditivo apresentou teores de MS e MO superiores ao da silagem controle $(0 \mathrm{~g} / \mathrm{kg}), \quad$ o que, provavelmente, seja resultado da maior efetividade do aditivo em reduzir as perdas de massa ocorridas durante todo o processo fermentativo neste tratamento.

A redução de MS está relacionada à diminuição no conteúdo celular, principalmente de carboidratos solúveis, durante $\mathrm{o}$ processo fermentativo, o que não foi observado no presente, pois, à medida que se adicionou a ureia como aditivo, o teor de MS foi aumentado; provavelmente o aditivo agiu diminuindo as perdas (Tab. 3) no processo fermentativo. 
Segundo Ítavo et al. (2010), os valores de MS (Tab. 1 e 2) dos tratamentos avaliados são considerados ideais para confecção de silagens de boa qualidade por proporcionarem facilidade na compactação da massa a ser ensilada, o que pode se refletir na redução das perdas durante a ensilagem.

Tabela 1. Composição química e digestibilidade in vitro da silagem de cana-de-açúcar com doses de ureia (U) como aditivo na ensilagem

\begin{tabular}{|c|c|c|c|c|c|c|c|c|}
\hline & \multicolumn{4}{|c|}{ Ureia (g/kg) } & \multicolumn{2}{|c|}{$\mathrm{P}$} & \multirow{2}{*}{ Equação de regressão } & \multirow{2}{*}{$r^{2}$} \\
\hline & 0 & 10 & 20 & 30 & $\mathrm{~L}$ & $\mathrm{Q}$ & & \\
\hline MS (\%) & 32,12 & 33,44 & 34,39 & 34,91 & 0,001 & 0,126 & $\mathrm{Y}=32,0203+0,07631 * \mathrm{U}$ & 0,90 \\
\hline MO (\% da MS) & 95,56 & 97,58 & 97,52 & 98,43 & 0,004 & 0,288 & $\mathrm{Y}=95,8695+0,08870 * \mathrm{U}$ & 0,91 \\
\hline PB (\% da MS) & 2,58 & 7,76 & 18,70 & 19,31 & $<0,001$ & $<0,001$ & $\mathrm{Y}=2,9160+0,611350 * \mathrm{U}$ & 0,91 \\
\hline $\mathrm{EE}$ (\% da MS) & 1,45 & 1,41 & 1,40 & 1,40 & 0,121 & 0,135 & $Y=1,41$ & - \\
\hline FDN (\% da MS) & 67,42 & 61,52 & 56,74 & 59,74 & 0,021 & 0,346 & $Y=66,8640-0,3235160 * U$ & 0,91 \\
\hline FDA (\% da MS) & 42,06 & 37,47 & 34,94 & 30,81 & $<0,001$ & 0,914 & $\mathrm{Y}=41,7640-0,362850 * \mathrm{U}$ & 0,99 \\
\hline DIVMS (\%) & 42,61 & 48,53 & 50,69 & 51,18 & 0,006 & $<0,001$ & $Y=44,0734+0,278728 * U$ & 0,95 \\
\hline DIVFDN (\%) & 38,81 & 39,23 & 41,06 & 43,46 & $<0,001$ & 0,017 & $\mathrm{Y}=38,2735+0,157850 * \mathrm{U}$ & 0,95 \\
\hline DIVFDA (\%) & 20,14 & 21,19 & 24,60 & 25,78 & 0,002 & 0,985 & $\mathrm{Y}=19,8795+0,203450 * \mathrm{U}$ & 0,94 \\
\hline
\end{tabular}

MS: matéria seca; MO: matéria orgânica; PB: proteína bruta; EE: extrato etéreo; FDN: fibra em detergente neutro; FDA: fibra em detergente ácido; DIVMS: digestibilidade in vitro da matéria seca; DIVFDN: digestibilidade in vitro da fibra em detergente neutro; DIVFDA: digestibilidade in vitro da fibra em detergente ácido.

O menor teor de MO observado na silagem de cana-de-açúcar com $0 \mathrm{~g} / \mathrm{kg}$ de ureia como aditivo provavelmente é resultado da maior produção de gases e efluentes oriundos da maior extensão de fermentações indesejáveis, decorrente principalmente da ação de leveduras.

O teor de $\mathrm{PB}$ da silagem foi melhorado à medida que foram aumentando as doses de ureia, pois a ureia utilizada como aditivo tinha $45 \%$ de Nitrogênio; assim, pode-se sugerir que o uso de ureia em silagens de cana-de-açúcar pode corrigir o baixo teor de PB da forragem colhida.

Ao passo que se adicionaram as doses de ureia, houve efeito linear negativo para os teores de FDN e FDA $(\mathrm{P}<0,05)$. A ureia como aditivo na ensilagem da cana-de-açúcar pode ter favorecido para que ocorresse hidrólise alcalina com solubilização da hemicelulose (Dias et al., 2011), reduzindo os teores de FDN.

A justificativa para a adição de ureia na forragem a ser ensilada baseia-se no aumento do teor de PB (Tab. 1) da silagem e ocorrência de transformação de ureia em $\mathrm{NH}_{3}$, que reage com água de modo a formar hidróxido de amônia, evidenciando o efeito da amonização, o que promove alterações físico-químicas nos teores dos constituintes da parede celular.

A DIVMS apresentou efeito linear positivo ao passo que se elevou a dose de ureia na ensilagem da cana-de-açúcar. Provavelmente isso pode ter ocorrido devido ao aumento no teor de PB decorrente do $\mathrm{N}$ contido na ureia e da solubilização da hemicelulose (Dias et al., 2011). Lopes et al. (2007), avaliando a silagem de canade-açúcar acrescida de ureia, verificaram maiores incrementos no coeficiente de digestibilidade da PB nas silagens tratadas com ureia, o que está relacionado à maior quantidade de $\mathrm{PB}$.

As DIVFDN e DIVFDA foram melhoradas conforme aumentou a dose de ureia (Tab. 1). Isso pode ser justificado em função da ação do hidróxido de amônia sobre os componentes da parede celular, o que reflete positivamente na digestibilidade dos constituintes celulares.

Siqueira et al. (2007) avaliaram 1,5\% (15g/kg) de ureia como aditivo para a cana-de-açúcar na ensilagem e verificaram o valor para a DIVMS de $37,7 \%$ para a silagem, valor este inferior ao encontrado no presente trabalho, indicando que, à medida que se aumenta a inclusão de ureia na ensilagem da cana-de-açúcar, a DIVMS é melhorada.

Em trabalho avaliando o valor nutritivo da silagem de cana-de-açúcar, aos 12 meses de idade, com $5 \mathrm{~g} / \mathrm{kg}$ de ureia como aditivo, Andrade et al. (2001) observaram valores para a composição nutricional da silagem de 20,93; 9,43; e 68,70\% para os teores de MS, PB e FDN. Para a digestibilidade da MS e FDN, os valores 
foram de 53,64 e 43,9\%, valor este semelhante ao encontrado no presente trabalho (Tab. 1) com a dose de $30 \mathrm{~g} / \mathrm{kg}$ (3\%); porém, a cana-de-açúcar utilizada pelos autores foi cana de primeiro ano e idade inferior à utilizada no presente trabalho, mostrando a eficiência do aditivo na melhoria da qualidade da silagem de cana-de-açúcar.

Pedroso et al. (2007), em estudo de silagens com adição de ureia $(10 \mathrm{~g} / \mathrm{kg})$, observaram elevação da DIVMS em relação à controle, de 45,40 para $50,25 \%$, e atribuiu esse aumento da DIVMS ao aumento do teor de PB, 4,34; 9,87; 16,60 e $22,7 \%$ de PB para as doses de $0,5,10$ e $15 \mathrm{~g} / \mathrm{kg}$ de ureia como aditivo na ensilagem da cana-deaçúcar, respectivamente, decorrente do $\mathrm{N}$ presente na ureia. No presente trabalho, os valores para PB foram abaixo dos encontrados por Pedroso et al. (2007), podendo ser justificados pelo teor de PB da cana-de-açúcar sem ureia.

Houve efeito significativo das doses de glicerina bruta na ensilagem da cana-de-açúcar nos teores de MS, PB, EE e DIVMS (Tab. 2). Com a inclusão crescente de glicerina bruta, $0,10,20$, 30 e $40 \mathrm{~g} / \mathrm{kg}$ de glicerina na ensilagem da canade-açúcar, os teores de MS apresentaram efeito linear crescente. Esse aumento pode ser explicado pela densidade da glicerina e suas propriedades higroscópicas, o que permite a ligação com as moléculas de água do material ensilado, aumentando assim a massa seca do material ensilado.

Santos et al. (2010) relatam que a silagem de cana-de-açúcar acrescida de ureia e aditivos absorventes (mandioca desidratada) apresenta melhor valor nutritivo, maior consumo e digestibilidade da $\mathrm{PB}$, o que pode ser observado nas Tabelas 1 e 2; quando se adicionou a ureia e a glicerina, o valor nutritivo da silagem foi melhorado.

Gomes (2013) observou redução dos valores médios de $\mathrm{PB}$ das silagens em relação à silagem controle, evento influenciado pelo fato de a glicerina não possuir substâncias nitrogenadas em sua composição; portanto, exerce efeito diluidor. O mesmo foi observado no presente trabalho; quando se adicionou glicerina como aditivo na ensilagem da cana-de-açúcar, o teor de $\mathrm{PB}$ apresentou comportamento linear negativo $(\mathrm{P}<0,05)$.

À medida que se adicionou a glicerina na ensilagem da cana-de-açúcar, houve aumento linear positivo no teor de EE (Tab. 2) após abertura do silo. Isso é justificado pela composição de EE da glicerina (10,80\%). Segundo Soares et al. (2010), a maior presença de contaminantes (óleo, álcool e catalizador) na glicerina bruta explicaria a maior proporção de EE (10,80\%).

Tabela 2. Composição bromatológica da silagem de cana com doses de glicerina (G) como aditivo na ensilagem

\begin{tabular}{|c|c|c|c|c|c|c|c|c|c|}
\hline & \multicolumn{5}{|c|}{ Glicerina (g/kg) } & \multicolumn{2}{|c|}{$\mathrm{P}$} & \multirow{2}{*}{ Equação de regressão } & \multirow{2}{*}{$r^{2}$} \\
\hline & 0 & 10 & 20 & 30 & 40 & $\mathrm{~L}$ & Q & & \\
\hline MS (\%) & 32,12 & 32,81 & 34,32 & 34,75 & 35,23 & $<0,001$ & 0,976 & $\mathrm{Y}=32,0378+0,083297 * \mathrm{G}$ & 0,87 \\
\hline MO (\% MS) & 95,56 & 96,43 & 96,01 & 96,30 & 96,13 & 0,213 & 0,162 & $Y=96,09$ & - \\
\hline PB (\% MS) & 2,58 & 1,76 & 1,68 & 1,62 & 1,60 & 0,029 & 0,021 & $Y=2,41971-0,0209639 * G$ & 0,67 \\
\hline EE (\% MS) & 1,45 & 3,03 & 3,62 & 3,41 & 4,38 & $<0,001$ & 0,037 & $\mathrm{Y}=2,11200+0,0564500 * \mathrm{G}$ & 0,85 \\
\hline FDN (\% MS) & 67,42 & 65,80 & 66,40 & 66,18 & 66,39 & 0,188 & 0,248 & $Y=66,44$ & - \\
\hline FDA (\% MS) & 42,06 & 39,75 & 40,22 & 39,90 & 40,38 & 0,965 & 0,136 & $\mathrm{Y}=40,46$ & - \\
\hline DIVMS (\%) & 49,61 & 52,24 & 53,28 & 55,60 & 56,09 & $<0,001$ & 0,037 & $\mathrm{Y}=50,6820+0,156250 * \mathrm{G}$ & 0,94 \\
\hline DIVFDN (\%) & 48,81 & 47,89 & 47,40 & 48,39 & 47,48 & 0,505 & 0,231 & $\mathrm{Y}=47,99$ & - \\
\hline DIVFDA (\%) & 27,74 & 26,34 & 26,63 & 27,35 & 26,23 & 0,987 & 0,114 & $Y=26,86$ & - \\
\hline
\end{tabular}

MS: matéria seca; MO: matéria orgânica; PB: proteína bruta; EE: extrato etéreo; FDN: fibra em detergente neutro; FDA: fibra em detergente ácido. DIVMS: digestibilidade in vitro da matéria seca; DIVFDN: digestibilidade in vitro da fibra em detergente neutro; DIVFDA: digestibilidade in vitro da fibra em detergente ácido; EPM: erro padrão da média.

A glicerina é caracterizada como um ingrediente energético, mostrando obter características energéticas e fermentativas, podendo assim ser um material promissor como aditivo para silagens, sendo capaz de enriquecer a densidade energética da silagem (Gomes, 2013), o que pode ser observado no presente trabalho com 0 aumento do EE da silagem. Segundo estudos 
feitos por Cerrate et al. (2006), além de servir como fonte de energia, a glicerina tem ação na inibição da atividade metabólica de alguns microrganismos prejudiciais à conservação e à qualidade da forragem.

Conforme se elevaram as doses de glicerina, a DIVMS aumentou linearmente (Tab. 2). Essa melhora na digestibilidade pode estar relacionada à melhora da fração energética da silagem, pois, quando se aumentou a dose de glicerina bruta, o teor de EE aumentou.

Gomes (2013), avaliando a glicerina como aditivo, também verificou o mesmo comportamento para a DIVMS, apresentando médias de 45,54; 53,03; 56,04; 64,45 e 68,70\% para as doses $0,5,10,15$ e $20 \%$ de glicerina, respectivamente, equivalendo a um aumento de 16,$6 ; 23,3 ; 41,5$ e $50,8 \%$ para as doses de 50 , 100, 150 e $200 \mathrm{~g} / \mathrm{kg}$ de glicerina, quando comparadas ao tratamento controle. É preciso destacar que Gomes (2013) trabalhou com doses elevadas de glicerina, sendo que, no presente trabalho, a dose máxima foi de $40 \mathrm{~g} / \mathrm{kg}$ de canade-açúcar, e, no trabalho de Gomes (2013), a menor dose foi de $50 \mathrm{~g} / \mathrm{kg}$.

A medida do valor de $\mathrm{pH}$ em silagens é um importante indicador da qualidade de fermentação, sendo inclusive possível classificar as silagens em termos de qualidade (Jobim et al., 2007). O pH para as doses de ureia (Tab. 3) apresentou efeito quadrático $(\mathrm{P}<0,001)$. Derivando a equação de regressão para o pH, encontra-se o ponto de máxima com a dose de $20,48 \mathrm{~g} / \mathrm{kg}$ de ureia na ensilagem da cana-deaçúcar com valor de $\mathrm{pH}$ de 4,2. Porém os valores de $\mathrm{pH}$ para as doses de ureia estão dentro dos recomendados pela literatura, que se têm atribuído valores de $\mathrm{pH}$ entre 3,8 e 4,2 (Tomich et al., 2004) como adequados às silagens bem conservadas.

Avaliando o valor nutritivo da silagem de canade-açúcar, aos 12 meses de idade, com $5 \mathrm{~g} / \mathrm{kg}$ de ureia como aditivo, Andrade et al. (2001) observaram valores para $\mathrm{pH}$ de 3,49. Da mesma forma, Sá Neto et al. (2013), avaliando silagem de cana-de-açúcar com Lactobacillus buchneri, encontraram o valor de 3,43 para a silagem sem aditivo. $\mathrm{O}$ valor de $\mathrm{pH}$ é igual ao encontrado no presente trabalho no tratamento sem ureia $(0 \mathrm{~g} / \mathrm{kg})$, sendo que, quando se foi incluindo ureia, os valores de $\mathrm{pH}$ foram aumentados. Apenas o tratamento controle apresentou $\mathrm{pH}$ abaixo do recomendado (3,29), porém demonstrando que houve fermentação dentro do silo e o material foi conservado.

Tabela 3. PH, nitrogênio amoniacal $\left(\mathrm{N}-\mathrm{NH}_{3}\right)$ e perdas (\% da MS) da silagem de cana com doses (g/kg) de ureia (U) na ensilagem

\begin{tabular}{|c|c|c|c|c|c|c|c|c|}
\hline \multirow{2}{*}{ Variável } & \multicolumn{4}{|c|}{ Ureia $(\mathrm{g} / \mathrm{kg})$} & \multicolumn{2}{|c|}{$\mathrm{P}$} & \multirow{2}{*}{ Equação de regressão } & \multirow{2}{*}{$r^{2}$} \\
\hline & 0 & 10 & 20 & 30 & $\mathrm{~L}$ & $\mathrm{Q}$ & & \\
\hline $\mathrm{pH}$ & 3,49 & 3,86 & 4,18 & 3,93 & $<0,001$ & $<0,001$ & $\mathrm{Y}=3,37725+0,083475 * \mathrm{U}-0,0020375 * \mathrm{U}^{2}$ & 0,99 \\
\hline $\mathrm{N}-\mathrm{NH}_{3}$ & 1,72 & 3,80 & 7,88 & 9,00 & $<0,001$ & 0,120 & $Y=1,71750+0,2590 * U$ & 0,90 \\
\hline Perdas & 6,69 & 5,74 & 4,22 & 4,16 & $<0,001$ & 0,113 & $Y=6,7735-0,09125 * U$ & 0,97 \\
\hline
\end{tabular}

Lopes e Evangelista (2010), avaliando a silagem de cana-de-açúcar com 15 g de ureia no momento da ensilagem, encontraram valor de $\mathrm{pH}$ da silagem de 6,48 , o que provavelmente ocorreu devido à lenta queda do $\mathrm{pH}$, em função da maior quantidade de ureia utilizada nesse tratamento, e interferiu na extensão da colonização da massa ensilada pelas bactérias ácidoláticas, favorecendo o crescimento de microrganismos indesejáveis que atuam em faixas de $\mathrm{pH}$ mais alto. Foi observado ainda que a silagem com $15 \mathrm{~g}$ de ureia como aditivo apresentou as piores características sensoriais no momento de abertura dos silos (cor escura e forte cheiro de amônia); o que não foi observado no presente trabalho.
Segundo McDonald et al. (1991), silagens com concentração de $\mathrm{N}_{-} \mathrm{NH}_{3}$ menor que $10 \%$ são classificadas com preservadas. As silagens com inclusão de ureia e glicerina atendem a essas recomendações (Tab. 3 e 4). Lopes e Evangelista (2010) relatam que a amônia originada da ação da urease sobre a ureia funciona como inibidor do crescimento de leveduras, o que pode refletir em menores perdas e favorecer a qualidade da silagem.

Ribeiro et al. (2010), utilizando ureia e $\mathrm{NaOH}$ como aditivos para ensilagem de cana-de-açúcar, verificaram efeito dos aditivos nos valores de $\mathrm{pH}$, apresentando valores de 4,24 para silagens 
com $4 \%$ de $\mathrm{NaOH}, 4,0$ para silagem com $2 \%$ de ureia $+2 \%$ de $\mathrm{NaOH}$, 3,3 para silagem com $4 \%$ de ureia, e 3,5 para silagem de cana-de-açúcar sem aditivo.

$\mathrm{O} \mathrm{N}-\mathrm{NH}_{3}$ é associado à qualidade fermentativa da silagem, pois é proveniente da degradação da fração proteica pelos clostrídeos (McDonald et al., 1991). Entretanto, na ensilagem da cana-deaçúcar, essa degradação deve ser inibida pela rápida queda do $\mathrm{pH}$, decorrente do baixo poder tampão e da presença abundante de carboidratos solúveis.

$\mathrm{O} \mathrm{N}-\mathrm{NH}_{3}$ apresentou efeito linear positivo, o aumento das doses de ureia ocasionou um aumento no $\mathrm{N}-\mathrm{NH}_{3}$. Esses aumentos estão relacionados à transformação da ureia em amônia. Essa reação parece a princípio indesejável, porém, na ensilagem de cana-deaçúcar, a presença de amônia pode consistir em vantagem, em virtude do controle de leveduras (Siqueira et al., 2007). Andrade et al. (2001) encontraram valores de $\mathrm{N}-\mathrm{NH}_{3}$ de 14,82 para silagem de cana-de-açúcar com $5 \mathrm{~g} / \mathrm{kg}$ de ureia como aditivo no momento da ensilagem.
$\mathrm{O} \mathrm{N}-\mathrm{NH}_{3}$ das silagens tratadas com ureia no presente trabalho encontram-se no limite máximo de 12\%, indicado por Mcdonald et al. (1991) na caracterização de material com boa conservação como silagem.

As doses foram significativas para redução das perdas por gases; à medida que se incluiu ureia na cana-de-açúcar na ensilagem, as perdas apresentaram efeito linear negativo $(\mathrm{P}<0,001)$, demonstrando que $\mathrm{o}$ aditivo proporcionou menores perdas por gases (Tab. 3). Ítavo et al. (2010) sugerem que o uso de ureia em silagens de cana-de-açúcar pode reduzir as perdas durante a ensilagem e corrigir o deficit proteico.

As doses de glicerina bruta (Tab. 4) não apresentaram efeito significativo para o $\mathrm{pH}$ e o $\mathrm{N}-\mathrm{NH}_{3}$, apresentando médias de 3,45 e 1,64, respectivamente. Bernardes et al. (2007) não observaram diferenças estatísticas no $\mathrm{pH}$ de silagens de cana-de-açúcar com e sem milho desintegrado com palha e sabugo, o mesmo observado no presente trabalho quando se adicionou glicerina bruta como aditivo na ensilagem.

Tabela 4. $\mathrm{PH}$, nitrogênio amoniacal $\left(\mathrm{N}-\mathrm{NH}_{3}\right)$ e perdas (\% da $\mathrm{MS}$ ) da silagem de cana com doses de glicerina bruta $(\mathrm{g} / \mathrm{kg})$ na ensilagem

\begin{tabular}{|c|c|c|c|c|c|c|c|c|c|}
\hline \multirow{2}{*}{ Variável } & \multicolumn{5}{|c|}{ Glicerina bruta (g/kg) } & \multicolumn{2}{|c|}{$\mathrm{P}$} & \multirow{2}{*}{ Equação de regressão } & \multirow{2}{*}{$r^{2}$} \\
\hline & 0 & 10 & 20 & 30 & 40 & $\mathrm{~L}$ & $\mathrm{Q}$ & & \\
\hline $\mathrm{pH}$ & 3,49 & 3,42 & 3,46 & 3,46 & 3,44 & 0,555 & 0,351 & $Y=3,45$ & - \\
\hline $\mathrm{N}-\mathrm{NH}_{3}$ & 1,72 & 1,62 & 1,61 & 1,68 & 1,58 & 0,608 & 0,900 & $Y=1,64$ & - \\
\hline Perdas & 6,69 & 5,97 & 5,89 & 5,51 & 5,48 & 0,010 & 0,036 & $Y=6,980514-0,04156 * G$ & 0,93 \\
\hline
\end{tabular}

Já para perdas por gases (\% da MS), as doses de glicerina bruta apresentaram efeito significativo com comportamento linear negativo, ou seja, ao passo que foi adicionado glicerina bruta na ensilagem da cana-de-açúcar, as perdas por gases foram diminuídas, caracterizando a resposta do aditivo em reduzir perdas durante o processo de fermentação (Tab. 4).

Lopes e Evangelista (2010), avaliando inclusão de aditivo na silagem de cana-de-açúcar, observaram que a inclusão de aditivo proporcionou maior teor de MS, resultado da maior efetividade do aditivo em reduzir as perdas ocorridas durante todo o processo fermentativo. Isso pode ter ocorrido no presente trabalho, pois, quando se elevou a dose de glicerina bruta, o teor de MS foi aumentado.
Ao adicionar ureia e glicerina bruta na ensilagem da cana-de-açúcar, as perdas foram reduzidas (Tab. 3 e 4) e os teores de MS das silagens foram aumentados. Pedroso et al. (2005), estudando a dinâmica de fermentação da cana-de-açúcar, encontraram perdas de MS até o $45^{\circ}$ dia após a ensilagem, atingindo, em média, 30\% da MS total da silagem e, a partir daí, mantendo-se constante até os 180 dias de fermentação. Segundo os autores, a principal forma dessas perdas deveu-se à produção de gases.

A ureia e a glicerina bruta podem ser utilizadas como aditivo na ensilagem da cana-de-açúcar. Doses crescentes de ureia como aditivo na ensilagem da cana-de-açúcar melhoraram a composição nutricional e os padrões fermentativos da silagem. A glicerina bruta em doses crescentes como aditivo na ensilagem da 
cana-de-açúcar melhora as características nutricionais da silagem e reduz perdas por gases. Há necessidade de mais estudos com a glicerina como aditivo na ensilagem de forrageiras.

\section{CONCLUSÕES}

Recomenda-se a utilização de até $30 \mathrm{~g} / \mathrm{kg}$ de ureia e de até $40 \mathrm{~g} / \mathrm{kg}$ de glicerina bruta na ensilagem da cana-de-açúcar, melhorando o valor nutritivo e as características fermentativas da silagem.

\section{REFERÊNCIAS}

ANDRADE, J.B.; FERRARI JÚNIOR, E.; BRAUN, G. Valor nutritivo da silagem de canade-açúcar tratada com ureia e acrescida de rolãode-milho. Pesq. Agrop. Bras., v.36, p.1169-1174, 2001.

ALLI, I.; FAIRBAIRN, R.; BAKER, B.E. The effects of ammonia on the fermentation of chopped sugarcane. Anim. Feed Sci. Tech., v.9, p.291-299, 1983.

BERNARDES, T.F.; REIS, R.A.; SIQUEIRA, G.R. et al. Avaliação da queima e da adição de milho desintegrado com palha e sabugo na ensilagem de cana-de-açúcar. Rev. Bras. Zootec., v.36, p.269-275, 2007.

BOLSEN, K.K.; LIN, C.; BRENT, B.E.; GADEKEN, D. Effect of silage additives on the microbial succession and fermentation process of alfalfa and corn silages. J. Dairy Sci., v.75, p.3066-3083, 1992.

CASTRO NETO, A.G.; MOLINA, L.R.; GONÇALVES, L.C.; JAYME, C.G. Parâmetros de fermentação de silagens de cana-de-açúcar submetidas a diferentes tratamentos. Arq. Bras. Med. Vet. Zootec., v.60, p.1150-1156, 2008.

CERRATE, S.; YAN, F.; WANG, Z. et al. Evaluation of glycerine from biodiesel production as a feed ingredient for broilers. Int. J. Poul. Sci., v.5, p.1001-1007, 2006.

DIAS, A.M.; ÍTAVO, L.C.V.; DAMASCENO, J.C. et al. Sugar cane treated with calcium hydroxide in diet for cattle: intake, digestibility of nutrients and ingestive behaviour. Rev. Bras. Zootec., v.40, p.1799-1806, 2011.
EVANGELISTA, A.R.; SIQUEIRA, G.R.; LIMA, J.A. et al. Perfil fermentativo de silagens de cana-de-açúcar com e sem inclusão de milho desintegrado com palha e sabugo. Rev. Bras. Zootec., v.38, p.20-26, 2009.

GOMES, M.A.B. Glicerina na qualidade de silagens de cana-de-açúcar e de milho e na produção de oócitos e de embriões in vitro de bovinos. 2013. 90f. Tese (Doutorado em Zootecnia) - Universidade Estadual de Maringá, Maringá.

ÍTAVO, L.C.V.; ÍTAVO, C.C.B.F.; MORAIS, M.G. et al. Composição química e parâmetros fermentativos de silagens de capim-elefante e cana-de-açúcar tratadas com aditivos. Rev. Bras. Saúde Prod. Anim., v.11, p.606-617, 2010.

JOBIM, C.C.; NUSSIO, L.G.; REIS, R.A.; SCHMIDT, P. Avanços metodológicos na avaliação da qualidade da forragem conservada. Rev. Bras. Zootec., v.36, p.101-120, 2007.

KERR, B.J.; WEBER, T.E.; DOZIER, W.A.; KIDD, M.T. Digestible and metabolizable energy content of crude glycerin originating from different sources in nursery pigs. J. Anim. Sci., v.87, p.4042-4049, 2009.

LOPES, J.; EVANGELISTA, A.R.; ROCHA, G.P. Valor nutricional da silagem de cana-deaçúcar acrescida de ureia e aditivos absorventes de umidade. Rev. Bras. Zootec., v.36, p.11551161, 2007.

LOPES, J.; EVANGELISTA, A.R. Características bromatológicas, fermentativas e população de leveduras de silagens de cana-deaçúcar acrescidas de ureia e aditivos absorventes de umidade. Rev. Bras. Zootec., v.39, p.984-991, 2010.

McDONALD, P.; HENDERSON, A.R.; HERON, S.J.E. The biochemistry of silage. 2.ed. Marlow: Chalcomb Publication, 1991. 340p.

PEDROSO, A.F.; NUSSIO, L.G.; PAZIANI, S.F. et al. Fermentation and epiphytic microflora dynamics in sugar cane silage. Sci. Agric., v.62, p.427-432, 2005.

PEDROSO, A.F.; NUSSIO L.G.; LOURES D.R.S. et al. Efeito do tratamento com aditivos químicos e inoculantes bacterianos nas perdas e na qualidade de silagens de cana-de-açúcar. Rev. Bras. Zootec., v.36, p.558-564, 2007. 
RIBEIRO, L.S.O; PIRES, A.J.V.; CARVALHO. G.G.P. et al. Composição química e perdas fermentativas de silagem de cana-de-açúcar tratada com ureia ou hidróxido de sódio. Rev. Bras. Zootec., v.39, p.1911-1918, 2010.

SÁ NETO, A.; NUSSIO, L.G.; ZOPOLLATTO, M. et al. Silagem de milho ou de cana-de-açúcar com Lactobacillus buchneri exclusivamente ou em associação com L. plantarum. Pesq. Agropec. Bras., v.48, p.528-535, 2013.

SANTOS, M.V.F.; GÓMEZ CASTRO, A.G.; PEREA, J.M. et al. Fatores que afetam o valor nutritivo da silagens de forrageiras tropicais. Arch. Zootec., v.59, p.25-43, 2010.

SILVA, D.J.; QUEIROZ, A.C. Análise de alimentos: métodos químicos e biológicos. 3.ed. Viçosa:UFV, 2002. 235p.
SIQUEIRA, G.R.; REIS, R.A.; SCHOCKENITURRINO, R.P. et al. Associação entre aditivos químicos e bacterianos na ensilagem de cana-deaçúcar. Rev. Bras. Zootec., v.36, p.789-798, 2007.

SOARES, C.M.; ÍTAVO, L.C.V.; DIAS, A.M. et al. Forage turnip, sunflower, and soybean biodiesel obtained by ethanol synthesis: Production protocols and thermal behavior. Fuel. v.89, p.3725-3729, 2010.

TOMICH, T.R.; GONÇALVES, L.C.; TOMICH, R.G.P. et al. Características químicas e digestibilidade in vitro de silagens de girassol. Rev. Bras. Zootec., v.33, p.1672-1682, 2004. 